\title{
Evaluating the utility of the female-specific mitochondrial f-orf gene for population genetic, phylogeographic and systematic studies in freshwater mussels (Bivalvia: Unionida)
}

\author{
Brent M Robicheau $^{1}$ ， Emily E Chase ${ }^{1}$ ， Walter R Hoeh ${ }^{2}$ ， John L Harris ${ }^{3}$ ， Donald T Stewart ${ }^{1}$, Sophie Breton \\ Corresp. 4 \\ 1 Department of Biology, Acadia University, Wolfville, Canada \\ Department of Biological Sciences, Kent State University, Kent, United States \\ 3 Department of Biological Sciences, Arkansas State University, Jonesboro, United States \\ 4 Department of Biological Sciences, University of Montreal, Montreal, Canada \\ Corresponding Author: Sophie Breton \\ Email address: s.breton@umontreal.ca
}

Freshwater mussels (order: Unionida) represent one of the most critically imperilled groups of animals; consequently there exists a need to establish a variety of molecular markers for population genetics and systematic studies in this group. Recently, two novel mitochondrial protein-coding genes were described in unionoids with doubly uniparental inheritance of mtDNA. These genes are the $f$-orf in female-transmitted mtDNA and the $m$ orf in male-transmitted mtDNA. In this study, whole F-type mitochondrial genome sequences of two morphologically similar Lampsilis spp. were compared to identify the most divergent protein-coding regions, including the $f$-orf gene, and evaluate its utility for population genetic and phylogeographic studies in the subfamily Ambleminae. We also tested whether the f-orf gene is phylogenetically informative at the species level. Our preliminary results indicated that the $f$-orf gene could represent a viable molecular marker for population- and species-level studies in freshwater mussels. 
1 Evaluating the utility of the female-specific mitochondrial $f$-orf gene for population genetic,

2 phylogeographic and systematic studies in freshwater mussels (Bivalvia: Unionida)

Brent M. Robicheau ${ }^{1, *}$, Emily E. Chase ${ }^{1, *}$, Walter R. Hoeh ${ }^{2}$, John L. Harris ${ }^{3}$, Donald T. Stewart ${ }^{1}$, Sophie Breton ${ }^{4,5}$

${ }^{1}$ Department of Biology, Acadia University, 33 Westwood Avenue, Wolfville, NS, Canada B4P 2R6

${ }^{2}$ Department of Biological Sciences, Kent State University, 256 Cunningham Hall Kent, OH, USA 44242

${ }^{3}$ Department of Biological Sciences, Arkansas State University, Lab Science East, Jonesboro, AR, USA 72467

${ }^{4}$ Département de Sciences Biologiques, Université de Montréal, 90 Avenue Vincent d’Indy, Montréal, QC, Canada H2V 2S9

* These authors contributed equally to this work.

\section{${ }^{5}$ Corresponding author:}

Sophie Breton

E-mail: s.breton@umontreal.ca

Phone: 514-343-6111 ext. \#7460

ORCID ID: 0000-0002-8286-486X

\section{Abstract}

5 Freshwater mussels (order: Unionida) represent one of the most critically imperilled groups of 6 animals; consequently there exists a need to establish a variety of molecular markers for 
7 population genetics and systematic studies in this group. Recently, two novel mitochondrial

8 protein-coding genes were described in unionoids with doubly uniparental inheritance of

9 mtDNA. These genes are the $f$-orf in female-transmitted mtDNA and the $m$-orf in male-

10 transmitted mtDNA. In this study, whole F-type mitochondrial genome sequences of two

11 morphologically similar Lampsilis spp. were compared to identify the most divergent protein-

12 coding regions, including the $f$-orf gene, and evaluate its utility for population genetic and

13 phylogeographic studies in the subfamily Ambleminae. We also tested whether the f-orf gene is

14 phylogenetically informative at the species level. Our preliminary results indicated that the $f$-orf

gene could represent a viable molecular marker for population- and species-level studies in freshwater mussels.

\section{Introduction}

Freshwater mussels (Bivalvia: Unionida) occur globally, except in Antarctica, with more than 800 estimated species (Bogan \& Roe, 2008). Despite high diversity, many species are critically imperilled (Regnier et al., 2009; Lopes-Lima et al., 2017). Approximately 70\% of the 200 North American species are endangered at some level (Lopes-Lima et al., 2017). Freshwater mussels are also well recognized for their water filtration capabilities, and for the production of obligate parasitic larvae that metamorphose on fish hosts (Regnier et al., 2009; Lopes-Lima et al., 2017). They also possess an unusual system of mitochondrial transmission called doubly uniparental inheritance (DUI), a characteristic shared with various other bivalves (Gusman et al., 2016). DUI is the only exception to the strictly maternal inheritance of mitochondrial DNA (mtDNA) in animals and is characterized by having two types of mtDNA in males (the maletransmitted or M-type mtDNA in germline cells and the female-transmitted or F-type mtDNA in 
30

soma), and usually one type (the F-type) in females (Breton et al., 2007). DNA divergence between $\mathrm{M}$ and $\mathrm{F}$ mtDNAs within a single male freshwater mussel can reach $>40 \%$ (DoucetBeaupré et al., 2010). Moreover, each sex-associated mtDNA contains a novel protein-coding gene in addition to the 13 typical genes involved in ATP production ( $m$-orf in M-type and $f$-orf in F-type mtDNA; Breton et al., 2009,2010; Milani et al., 2013). These genes are among the fastest evolving $\mathrm{mt}$ genes in freshwater mussels (Breton et al., 2011; Mitchell et al., 2016). They also have hypothesized roles in the maintenance of DUI and sex determination in bivalves (Breton et al., 2011), with recent in silico analyses supporting such hypotheses (Mitchell et al., 2016). Molecular techniques are commonly used to study freshwater mussels (Mulvey et al., 1997; Krebs, 2004; Campbell et al., 2008) since shell morphology alone is often inadequate to define populations, species or subfamilies. Environmental conditions can affect shell developmental patterns and obfuscate taxonomic identification (Bogan \& Roe, 2008). Recent divergence (and retention of ancestral morphological characteristics) and hybridization phenomena also make shell characters only partially efficient in discriminating certain populations or lineages (Hoeh et al., 1995; Cyr et al., 2017). For example, significant genetic differences have been discovered in Utterbackia populations with little to no apparent differences in shell morphology (Hoeh et al., 1995). Several studies have used both F- and Mtype mtDNA sequences. For example, fragments of the $16 \mathrm{~S}$ rRNA and cytochrome c oxidase subunit I (coxl) genes obtained with the universal primers 16Sar-5 and 16Sbr-3 (Palumbi, 1997) and HCO2198 and LCO1490 (Folmer et al., 1994), respectively [or with modified versions of the latter two (Walker et al., 2006)], have been used to answer systematic, phylogenetic (Krebs, 2004; Krebs et al., 2013; Doucet-Beaupré et al., 2012) and phylogeographical (Mioduchowska et al., 2016) questions about freshwater mussels. Since the M-type mt genomes typically evolve 
53 faster than their F-type counterpart in freshwater mussels (Krebs, 2004; Gusman et al., 2016), relatively older (i.e. species- or family-level) divergences may be tracked more accurately with analyses of the more slowly evolving F-type mtDNA, while analyses of relatively recent (e.g. population-level) divergences may be facilitated by analyses of the faster evolving M-type mtDNA. For example, only the faster evolving male form of the 16S rRNA gene provided strong evidence of geographical isolation among Pyganodon grandis populations from the southern region of the Lake Erie watershed (Ohio, USA) (Krebs, 2004). However, because the male mtDNA is restricted to the testes, this requires identification of males, and this is impossible with juvenile specimens or with larvae (glochidia). Moreover, the precarious situation of several freshwater mussel species sometimes require non-destructive sampling of animals (e.g. using mantle snips and thus with no access to the M-type mtDNA), which are then returned to the river bottom (Inoue et al., 2014).

To explore species boundaries, evolutionary relationships and geographic distribution of freshwater mussel species, researchers also tried other protein-coding loci of the F-type mtDNA such as cytochrome c oxidase subunit II (cox2; Doucet-Beaupré et al., 2012) and NADH dehydrogenase subunit 1 (nadl; Campbell et al., 2005). For example, Campbell et al., (2005) used nadl together with coxl and 16S rRNA to study the phylogenetic diversity of the subfamily Ambleminae, but their data could not resolve all the tribes (Amblemini, Lampsilini, Pleurobemini, Quadrulini) as monophyletic assemblages. The same three gene fragments were also found to be poor at resolving recent relationships (intrageneric level) by other researchers (e.g., Sommer, 2007; McCartney et al., 2016).

Recently, Wares (2014) used a straightforward approach and compared whole mitochondrial genome sequences of recently-diverged taxa to identify the most divergent 
76

protein-coding region and verify its utility for population genetics (see also Shearer \& Coffroth, 2008) and systematic studies in scleractinian corals. Although its results suggested that this region alone (cytochrome b, cytb) was unlikely to improve researchers' ability to separate coral taxa using DNA sequence-based methods, the proposed pipeline, i.e. to find the most divergent region and to analyze its divergence across available GenBank data, could certainly be adopted to find another useful F-type mitochondrial region for population genetics and systematic studies in freshwater mussels.

Following Wares' pipeline, we focused on Ambleminae, an important freshwater mussel subfamily with several species listed as threatened or endangered (IUCN 2015), and searched for another useful region in the F-type mtDNA to explore phylogenetic diversity and phylogeographic or population genetic structure in this taxa. We compared F mt genomes between two putative species (i.e., two species that are difficult to tell apart morphologically), the Arkansas Fatmucket, Lampsilis powellii (I. Lea, 1852) and the Fatmucket, Lampsilis siliquoidea (Barnes, 1823) (Harris et al., 2004, 2010; Krebs et al., 2013), and identify highly divergent protein-coding regions such as the $f$-orf gene. We then analyzed sequence divergence in this region (and test whether it is phylogenetically informative) across available amblemine data as a first step to see if it could represent a viable molecular marker for population- and species-level studies in freshwater mussels.

\section{Materials and Methods}

Lampsilis mussels were collected from two major river drainages in the state of Arkansas: Ouachita River drainage - Ouachita River (Polk County = isolate H2610), and Red River drainage - Mountain Fork Little River (Polk County $=$ isolate H2655). Specimens were obtained 
99

100

101

102

103

104

105

106

107

108

109

110

111

112

113

114

115

116

117

under permit, including Arkansas Game and Fish Commission Scientific Collection Permits Nos. 022220078 and 062220101, and Federal Fish and Wildlife Permit No. TE079883-2 issued to JL Harris. Samples were identified as Lampsilis siliquoidea or L. powellii according to Harris et al. (2004, 2010), i.e. based on external shell morphology (color rays absent, pit rays present, nacre color matte yellow to $\tan =L$. powellii; color rays present, pit rays absent, nacre color shiny yellow to $\tan =L$. siliquoidea ). Each individual was sexed through microscopic examination of gonad tissues. Total DNA was extracted from female mantles to obtain the female-transmitted mtDNA using a QIAGEN DNeasy animal kit following the manufacturer's protocol. Complete mtDNAs were PCR amplified, according to the method of Breton et al. (2011) using primers listed in Table 1. Purified products were sequenced using FLX sequencing (McGill University and Genome Quebec Innovation Centre).

Sequences were assembled with MacVector v10.0 (Rastogi, 1999), annotated using MITOS (Bernt et al., 2013), and compared to published freshwater mussel mtDNAs. Further assessment of tRNA genes used tRNAScan-SE v1.21 (Lowe \& Eddy, 1997). MUSCLE (Edgar, 2004) was used within Geneious v10.0.9 (Kearse et al., 2012) to align complete mtDNAs.

Nucleotide divergence $\mathrm{K}(\mathrm{JC})$ across F-to-F mt genomes was determined with DnaSP v5 [slidingwindow $=500 \mathrm{bp}$; step size $=25 \mathrm{bp}]($ Librado \& Rozas, 2009).

DNA alignments of individual genes were produced via MUSCLE in MEGA7 (Kumar et al., 2016). MEGA7 was used to: determine p-distances and $d N / d S$ values $(d N=$ nonsynonymous substitutions/nonsynonymous sites; $d S=$ synonymous substitutions/synonymous sites), calculate Z-tests, and generate trees. The best substitution model for each gene was chosen via a model selection test in MEGA7, alignments were manually trimmed to start/end positions without gaps, and Maximum-likelihood (ML) trees were generated with 500 bootstrap replicates (complete 
122 deletion was used to account for gaps in ML trees). Bayesian inference trees were produced via 123 BEAST v2.4.6 (Drummond et al., 2012), using a Hasegawa-Kishino-Yano model for f-orf and a

124 Tamura-Nei evolutionary model for coxl (based on BEAST modeltest results), a Yule speciation

125 process, and 80 million Markov chain Monte Carlos steps (sampling every 1000 steps). A 10\%

126 burn in was used and resulting trees were compiled into the highest probability topology using

127 TreeAnnotator v1.4 (Rambaut \& Drummond, 2002). Graphs were produced using ggplot2 within

$128 \mathrm{R}$ (R Core Team, 2015). Specimens used in our phylogenetic analyses and in analysis of $f$-orf and

129 cox 1 sequences variability are described in Table 2. Nomenclature followed Williams et al.

130 (2017). Mitochondrial genomes were deposited in GenBank (accession nos. MF326971 and

131 MF326973).

\section{Results}

Mitochondrial genome sizes ( $\mathrm{F}=16,043$ and 16,990 bp for L. powelli and L. siliquoidea, respectively), gene order and compositions are consistent with those of other freshwater mussels (Doucet-Beaupré et al., 2010). We detected one large, potentially species-specific indel: a 51 bp indel in the $\operatorname{cox} 2 /$ nad 3 spacer region between the two F genomes.

Individual gene p-distances and $d N / d S$ ratios are given in Fig. 1. Our results show, consistent with the degree of nucleotide divergence across $\mathrm{mt}$ genes in F genomes (supplementary Figure S1), that the $f$-orf gene is among the least conserved genes in $\mathrm{F}$ genomes (Fig. 1). Only atp 8 has a higher $d N / d S$ ratio $(>0.4)$ than $f$-orf, although a Z-test for selection indicated that the probability of rejecting the null hypothesis of $d N=d S$ (neutrality) for this gene was 0.092 . 
144

145

146

147

148

149

150

151

152

153

154

155

156

157

158

159

160

161

162

163

164

165

166

Phylogenetic analyses focused on the $f$-orf gene because several $f$-orf $f$ sequences are available in GenBank compare to atp8. Three Bayesian phylogenetic trees were built for Ambleminae using: the f-orf gene (Fig. 2A), the standard animal mitochondrial cox 1 DNA barcode (Hebert et al., 2003; Fig. 2B), and both genes concatenated (Fig. 2C). Corresponding ML analyses are in supplementary Figure S2. The $f$-orf sequences led to better bootstrap values than cox1. Moreover, members of Toxolasma were grouped as a single clade only in the f-orf tree. Similar results were obtained with ML analyses. BI and ML trees with the highest bootstrap values were obtained using both $f$-orf and cox 1 together.

We further examined Ambleminae $f$-orf variability, again using cox 1 for comparison (Fig. 3). For the f-orf gene, intraspecific comparisons have lower variability and smaller pdistances $($ range $=0.000-0.011)$ versus coxl $($ range $=0.000-0.031)$, and intrageneric comparisons for the $f$-orf gene have overall greater $\mathrm{p}$-distances.

\section{Discussion}

Our research objective was to provide guidance towards the identification of another useful region in the F-type mtDNA to explore phylogenetic diversity and phylogeographic or population genetic structure in freshwater mussels. As pointed out by Wares (2014), finding gene regions that provide sufficient information, above and beyond the variation found within a population, might be challenging and we agree with him that it may be more optimal to first explore available genomic data (mitochondrial or whole mtDNA) rather than only use available primer regions or the same gene region that has proven useful in other animal species. In this study, we show that f-orf and also atp 8 show high divergence between morphologically similar members of Lampsilis. Although atp 8 had the highest $d N / d S$ ratios, the pattern was consistent 
167

168

169

170

171

172

173

174

175

176

177

178

179

180

181

182

183

184

185

186

187

188

189

with neutrality. This gene has historically been either missing and/or found to be the least conserved in bivalve mtDNAs (Breton et al., 2010). Therefore, it is not surprising that it evolves in a different manner than all other mt genes.

Based on divergence data, f-orf and atp 8 could thus represent valuable molecular markers in the context of population genetic studies in Ambleminae. Such genes, and in particularf-orf, could also potentially help test the hypothetical involvement of mitochondria and their genomes in establishing reproductive barriers and speciation events (Gershoni et al., 2009). The general research trend has shown the involvement of sex-linked genes in reproductive isolation (Qvarnström \& Bailey, 2009), therefore, demonstrating the participation of F- and M-ORF proteins in sex determination, as predicted by Breton et al., (2011), would particularly corroborate the potential of mitochondrial genetic speciation mechanisms. There were not enough atp 8 sequences (or whole mitochondrial genome sequences) available in GenBank for Ambleminae to see if they could be more informative for population genetic or species delineation studies, however, enough $f$-orf sequences were available to achieve the brief goal of our study.

At the species level, an optimal marker should have a fairly high level of sequence variability, but at the same time it should be sufficiently conserved to reduce phylogenetic noise. Analyses have suggested the systematic usefulness of the $f$-orf gene, while atp 8 appears too noisy. We proceeded with phylogenetic analyses using $f$-orf compared to cox 1 to evaluate the systematic utility of this gene. The f-orf BI phylogeny, like cox 1, was able to distinguish $L$. siliquoidea from L. powellii with high bootstrap support. Overall, our data suggest that both genes are somewhat limited in fully resolving Ambleminae phylogenies on their own, which is illustrated by each tree having relatively low bootstrap values. However, in combination, $f$ - 
190

191

orftcoxl produced a phylogeny with higher bootstraps, indicating their value for systematic studies.

We further determined $\mathrm{p}$-distances in $f$-orf and coxl for more sequences within the same lineages. These preliminary data suggest that at the population level, the $f$-orf gene displays relatively fewer nucleotide differences within species, while within genera, there are a relatively larger number of differences (compared to $\operatorname{coxl}$ ). This point is exemplified by $f$-orfs typically having $>20 \%$ sequence differences between species of the same genus (with the exception of the anomalous Toxolasma species pair that had a p-distance of $<0.05$ ).

\section{Conclusion}

This preliminary study indicates that the f-orf gene in freshwater mussels could represent a viable molecular marker for population- and species-level studies. This is based on: (1) the $f$-orf gene experiencing a high degree of relaxed purifying selection; (2) the f-orf gene, especially when used in combination with coxl (and it remains to be seen whether it is the case with other genes), can be phylogenetically informative, and (3) our detection of generally low withinspecies variability for the $f$-orf, and relatively high between-species variability for most closely related taxa.

\section{Acknowledgements}

The following are thanked for providing specimens or assisting with collections: C.L. Davidson, D.M. Hayes, W.R. Posey II and J.H. Seagraves. We also thank Manuel Lopes-Lima and two anonymous reviewers for insightful criticisms and suggestions. 
213

214

\section{References}

\section{Bernt M, Donath A, Jühling F, Externbrink F, Florentz C, Fritzsch G, Pütz J, Middendorf} M, Stadler PF. 2013. MITOS: improved de novo metazoan mitochondrial genome annotation. Molecular Phylogenetics and Evolution 69(2):313-319.

Bogan AE, Hoeh WR. 2000. On becoming cemented: evolutionary relationships among the genera in the freshwater bivalve family Etheriidae (Bivalvia: Unionoida). Pp. 159-168 in E.M. Harper, J.D. Taylor, J.A. Crane, editors. The evolutionary biology of the bivalvia. London: Geological Society, Special Publications.

Bogan AE, Roe KJ. 2008. Freshwater bivalve (Unioniformes) diversity, systematics, and evolution: status and future directions. Journal of the North American Benthological Society 27(2):349-369.

Boyer SL, Howe AA, Juergens NW, Hove MC. 2011. A DNA-barcoding approach to identifying juvenile freshwater mussels (Bivalvia: Unionidae) recovered from naturally infested fishes. Journal of the North American Benthological Society 30(1):182-194.

Breton S, Beaupré HD, Stewart DT, Hoeh WR, Blier PU. 2007. The unusual system of doubly uniparental inheritance of mtDNA: isn't one enough? Trends in Genetics 23(9):465-474.

\section{Breton S, Beaupré HD, Stewart DT, Piontkivska H, Karmakar M, Bogan AE, Blier PU,} Hoeh WR. 2009. Comparative mitochondrial genomics of freshwater mussels (Bivalvia: Unionoida) with doubly uniparental inheritance of mtDNA: gender-specific open reading frames and putative origins of replication. Genetics 183(4):1575-1589. 
Breton S, Stewart DT, Hoeh WR. 2010. Characterization of a mitochondrial ORF from the gender-associated mtDNAs of Mytilus spp. (Bivalvia: Mytilidae): identification of the «missing » ATPase 8 gene. Marine Genomics 3(1):11-18.

Breton S, Ghiselli F, Passamonti M, Milani L, Stewart DT, Hoeh WR. 2011a. Evidence for a fourteenth mtDNA-encoded protein in the female-transmitted mtDNA of marine mussels (Bivalvia: Mytilidae). PLoS ONE 6:19365.

\section{Breton S, Stewart DT, Shepardson S, Trdan RJ, Bogan AE, Chapman EG, Ruminas A,} Piontkivska H, Hoeh WR. 2011b. Novel protein genes in animal mtDNA: a new sex determination system in freshwater mussels (Bivalvia: Unionoida)? Molecular Biology and Evolution 28(5):1645-1659.

Burdick RC, White MM. 2007. Phylogeography of the Wabash pigtoe, Fusconaia flava (Rafinesque, 1820) (Bivalvia: Unionidae). Journal of Molluscan Studies 73(4):367-375.

Campbell DC, Serb JM, Buhay JE, Roe KJ, Minton RL, Lydeard. 2005. Phylogeny of North American amblemines (Bivalvia, Unionoida): prodigious polyphyly proves pervasive across genera. Invertebrate Biology 124(2):131-164.

Campbell DC, Johnson PD, Williams JD, Rindsberg AK, Serb JS, Small KK, Lydeard C. 2008. Identification of 'extinct' freshwater mussel species using DNA barcoding. Molecular Ecology Resources 8(4):711-724.

Campbell D, Lydeard C. 2012. The genera of Pleurobemini (Bivalvia: Unionidae: Ambleminae). American Malacological Bulletin 30(1):19-38.

Chapman EG, Piontkivska H, Walker JM, Stewart DT, Curole JP, Hoeh WR. 2008. Extreme primary and secondary protein structure variability in the chimeric maletransmitted cytochrome c oxidase subunit II protein in freshwater mussels: evidence for an 
elevated amino acid substitution rate in the face of domain-specific purifying selection. BMC Evolutionary Biology 8:165.

Curole JP, Kocher TD. 2002. Ancient sex-specific extension of the cytochrome c oxidase II gene in bivalves and the fidelity of doubly-uniparental inheritance. Molecular Biology and Evolution 19(8):1323-1328.

Cyr F, Paquet A, Martel AL, Angers B. 2007. Cryptic lineages and hybridization in freshwater mussels of the genus Pyganodon (Unionidae) in northeastern North America. Canadian Journal of Zoology 85(12):1216-1227.

Doucet-Beaupré H, Breton S, Chapman EG, Blier PU, Bogan AE, Stewart DT, Hoeh WR. 2010. Mitochondrial phylogenomics of the Bivalvia (Mollusca): searching for the origin and mitogenomic correlates of doubly uniparental inheritance of mtDNA. $B M C$ Evolutionary Biology 10:50.

Doucet-Beaupré H, Blier PU, Chapman EG, Piontkivska H, Sietman BE, Mulcrone RS, Hoeh WR. 2012. Pyganodon (Bivalvia: Unionoida: Unionidae) phylogenetics: A maleand female-transmitted mitochondrial DNA perspective. Molecular Phylogenetics and Evolution 63(2):430-444.

Drummond AJ, Suchard MA, Xie D, Rambaut A. 2012. Bayesian Phylogenetics with BEAUti and the BEAST 1.7. Molecular Biology and Evolution 29(8):1969-1973.

Edgar RC. 2004. MUSCLE: multiple sequence alignment with high accuracy and high throughput. Nucleic Acids Research 32(5):1792-1797.

Folmer O, Black M, Hoeh WR, Lutz R, Vrijenhoek RDNA. 1994. Primers for the amplification of mitochondrial cytochrome c oxidase subunit I from diverse metazoan invertebrates. Molecular Marine Biology and Biotechnology 3(5):294-299. 
Gershoni M, Templeton AR, Mishmar D. 2009. Mitochondrial bioenergetics as a major motive force of speciation. Bioessays 31(6):642-650.

Gusman A, Lecomte S, Stewart DT, Passamonti M, Breton S. 2016. Pursuing the quest for better understanding the taxonomic distribution of the system of doubly uniparental inheritance of mtDNA. PeerJ 4:e2760.

Harris JL, Hoeh WR, Christian AD, Walker JL, Farris JL, Johnson RL, Gordon ME. 2004. Species limits and phylogeography of Lampsilinae (Bivalvia; Unionoida) in Arkansas with emphasis on species of Lampsilis. Little Rock: Final report to Arkansas Game and Fish Commission.

Harris JL, Posey WR, Davidson CL, Farris JL, Oetker SR, Stoeckel JN, Grump BG, Barnett MS, Martin HC, Seagraves JH, Matthews MW, Winterringer R, Osborne C, Christian AD, Wentz NJ. 2010. Unionoida (Mollusca: Margaritiferidae, Unionidae) in Arkansas, third status review. Journal of the Arkansas Academy of Science 63:50-86.

Hebert PDN, Ratnasingham S, de Waard JR. 2003. Barcoding animal life: cytochrome c oxidase subunit 1 divergences among closely related species. Proceedings of the Royal Society London B Biological Sciences 270:S96-S99.

Hoeh WR, Frazer KS, Naranjo-Garcia E, Trdan RJ. 1995. A phylogenetic perspective on the evolution of simultaneous hermaphroditism in a freshwater mussel clade (Bivalvia: Unionidae: Utterbackia). Malacological Review 28(1-2):43-60.

Inoue K, Hayes DM, Harris JL, Christian AD. 2013. Phylogenetic and morphometric analyses reveal ecophenotypic plasticity in freshwater mussels Obovaria jacksoniana and Villosa arkansasensis (Bivalvia: Unionidae). Ecology and Evolution 3(8):2670-2683. 
Kearse M, Moir R, Wilson A, Stones-Havas S, Cheung M, Sturrock S, Buxton S, Cooper A, Markowitz S, Duran C, Thierer T, Ashton B, Meintjes P, Drummond A. 2012. Geneious Basic: an integrated and extendable desktop software platform for the organization and analysis of sequence data. Bioinformatics 28(12):1647-1649.

Krebs RA. 2004. Combining paternally and maternally inherited mitochondrial DNA for analysis of population structure in mussels. Molecular Ecology 13(6):1701-1705.

Krebs RA, Borden WC, Evans NM, Doerder FP. 2013. Differences in population structure estimated within maternally- and paternally-inherited forms of mitochondria in Lampsilis siliquoidea (Bivalvia: Unionidae). Biological Journal of the Linnean Society London 109(1):229-240.

Kumar S, Stecher G, Tamura K. 2016. MEGA7: Molecular Evolutionary Genetics Analysis version 7.0 for bigger datasets. Molecular Biology and Evolution 33(7):1870-1874.

IUCN. 2015. The IUCN Red List of Threatened Species. Version 2015-4. $<$ http://www.iucnredlist.org $>$.

Librado P, Rozas J. 2009. DnaSP v5: a software for comprehensive analysis of DNA polymorphism data. Bioinformatics 25(11):1451-1452.

Lopes-Lima M, Sousa R, Geist J, Aldridge DC, Araujo R, Bergengren J, Bespalaya Y, Bodis E, Burlakova L, Van Damme D, Douda K, Froufe E, Georgiev D, Gumpinger C, Karatayev A, Kebapçi U, Killeen I, Lajtner J, Larsen BM, Lauceri R, Legakis A, Lois S, Lundberg S, Moorkens E, Motte G, Nagel KO, Ondina P, Outeiro A, Paunovic M, Prié V, von Proschwitz T, Riccardi N, Rudsite M, Rudzitis M, Scheder C, Seddon M, Sereflisan H, Simic V, Sokolova S, Stoeckl K, Taskinen J, Teixeira A, Thielen F, Trichkova T, Varandas S, Vicentini H, Zajac K, Zajac T, Zogaris S. 2017. 
Conservation status of freshwater mussels in Europe: state of the art and future challenges. Biological Reviews of the Cambridge Philosophical Society 92(1):572-607.

Lowe TM, Eddy SR. 1997. tRNAscan-SE: a program for improved detection of transfer RNA genes in genomic sequence. Nucleic Acids Research 25(5):955-964.

Mathias PT, Hoffman JR, Wilson CC, Zanatta DT. 2018. Signature of postglacial colonization on contemporary genetic structure and diversity of Quadrula quadrula (Bivalvia: Unionidae). Hydrobiologia 810(1):207-225.

McCartney MA, Bogan AE, Sommer KM, Wilbur AE. 2016. Phylogenetic analysis of lake Waccamaw endemic freshwater mussel species. American Malacological Bulletin 34(2):109-120.

Milani L, Ghiselli F, Guerra D, Breton S, Passamonti M. 2013. A Comparative Analysis of Mitochondrial ORFans: New Clues on Their Origin and Role in Species with Doubly Uniparental Inheritance of Mitochondria. Genome Biology and Evolution 5(7):1408-1434.

Mioduchowska M, Kaczmarczyk A, Zając K, Zając T, Sell J. 2016. Gender-associated mitochondrial DNA heteroplasmy in somatic tissues of the endangered freshwater mussel Unio crassus (Bivalvia: Unionidae): Implications for sex identification and phylogeographical studies. Journal of Experimental Zoology A Ecological and Inegrative Physiology 325(9):610-625.

Mitchell A, Guerra D, Stewart DT, Breton S. 2016. In silico analyses of mitochondrial ORFans in freshwater mussels (Bivalvia: Unionoida) provide a framework for future studies of their origin and function. BMC Genomics 17:597. 
Mulvey M, Lydeard C, Pyer DL, Hicks KM, Brim-Box J, Williams JD, Butler RS. 1997. Conservation genetics of North American freshwater mussels Amblema and Megalonaias. Conservation Biology 11(4):868-878.

Palumbi S, Martin A, Romano WO, McMillan L, Stice L, Grabowski G. 1991. The simple fools guide to PCR, version II. Honolulu: University of Hawaii.

Pfeiffer JM, Johnson NA, Randklev CR, Howells RG, Williams JD. 2016. Generic reclassification and species boundaries in the rediscovered freshwater mussel 'Quadrula' mitchelli (Simpson in Dall, 1896). Conservation Genetics 17(2):279-292.

Qvarnström A, Bailey RI. 2009. Speciation through evolution of sex-linked genes. Heredity 102:4-15.

R Core Team. 2015. R: A language and environment for statistical computing. Available from: https://www.r-project.org.

Rambaut A, Drummond A. 2002. Tree Annotator version 1.4 part of the BEAST package.

Rastogi P. 1999. MacVector. In: Misener M and Krawetz S (eds). Bioinformatics Methods and Protocols: Methods in Molecular Biology. Humana Press, New Jersey, pp 47-69.

Regnier C, Fontaine B, Bouchet P. 2009. Not knowing, not recording, not listing: numerous unnoticed mollusk extinctions. Conservation Biology 23(5):1214-1221.

Roe KJ, Hartfield PD, Lydeard C. 2001. Phylogeographic analysis of the threatened and endangered superconglutinate-producing mussels of the genus Lampsilis (Bivalvia: Unionidae). Molecular Ecology 10(9):2225-2234.

Serb JM, Lydeard C. 2003. Complete mtDNA sequence of the North American freshwater mussel, Lampsilis ornata (Unionidae): an examination of the evolution and phylogenetic 
utility of mitochondrial genome organization in Bivalvia (Mollusca). Molecular Biology and Evolution 20(11):1854-1866.

Shearer TL, Coffroth MA. 2008. DNA BARCODING: Barcoding corals: limited by interspecific divergence, not intraspecific variation. Molecular Ecology Resources 8(2):247-255.

Sommer K. 2007. Genetic identification and phylogenetics of Lake Waccamaw endemic freshwater mussel species. M.S. Thesis, Department of Biology and Marine Biology. University of North Carolina, Wilmington, Wilmington, NC.

Walker JM, Curole JP, Wade DE, Hoeh WR. 2006. Taxonomic distribution and phylogenetic utility of gender-associated mitochondrial genomes in the Unionoida (Bivalvia). Malacologia 48:265-284.

Wares JP. 2014. Mitochondrial cytochrome b sequence data are not an improvement for species identification in scleractinian corals. PeerJ 2:e564; DOI 10.7717/peerj.564

Williams JD, Bogan AE, Butler RS, Cummings KS, Garner JT, Harris JL, Johnson NA, Watters GT. 2017. A revised list of the freshwater mussels (Mollusca: Bivalvia: Unionida) of the United States and Canada. Freshwater Mollusk Biology and Conservation 20(2):33-58.

\section{Figure Legends}




\section{1}

Fig. 1. Nucleotide distances calculated for individual mitochondrial gene comparisons. (A) $d N / d S$ ratios/scores; (B) p-distance scores.

Fig. 2. Bayesian inference (BI) trees produced in BEAUti and BEAST 2.4.6 for (A) f-orf, (B) coxl, and (C) concatenated f-orf and coxl sequences also used in maximum likelihood trees of Fig. S2. (A) was produced using a Hasegawa-Kishino-Yano model, (B) a Tamura-Nei model and (C) both these models of nucleotide substitution. Sequences used in BI trees refer to those listed and starred in Table 2.

\section{Fig. 3. The distribution of pair-wise p-distance scores for $f$-orf and cox 1 genes within}

Ambleminae. The taxa compared are listed in Table 2. Intrageneric comparisons exclude intraspecific comparisons.

8

9

0

\section{2}

\section{Supporting information}

Figure S1. Sliding window analysis of nucleotide divergence between F-versus-F genomes. Analysis was conducted using a window size of 500bp and $25 \mathrm{bp}$ jumps. JC $=$ Jukes Cantor correction. Light grey blocks represent protein-coding OXPHOS and ribosomal RNA gene regions, while the novel f-orf gene is highlighted dark grey. Dashed lines indicate the midpoint of genes. 
419 Figure S2. Maximum-likelihood Ambleminae trees for $f$-orf $(\mathrm{A}), \operatorname{cox} 1$ (B), and concatenated

$420 \boldsymbol{f}$-orf $+\operatorname{cox} 1$ sequences (C). Samples/sequences used are described in Table 2. Substitution 421 models selected (Hasegawa-Kishino-Yano (HKY) $+\mathrm{G}$ for $f$-orf, Tamura-Nei (TN93) $+\mathrm{G}+\mathrm{I}$ for 422 coxl, and TN93 +G for $f$-orf $+\operatorname{cox} 1)$ were based on running alignments through MEGA's model 423 selection analysis. The best models for individual gene alignments had the lowest BIC scores for 424 each gene. The top most similar model between the two individual model tests was chosen as the 425 best model for the concatenated gene tree (again based on lowest BIC scores). Bootstrap 426 percentage values based on 500 replicates are shown to the left of nodes. 


\section{Figure 1}

Nucleotide distances calculated for individual mitochondrial gene comparisons.

(A) $d N / d S$ ratios/scores; (B) p-distance scores. 


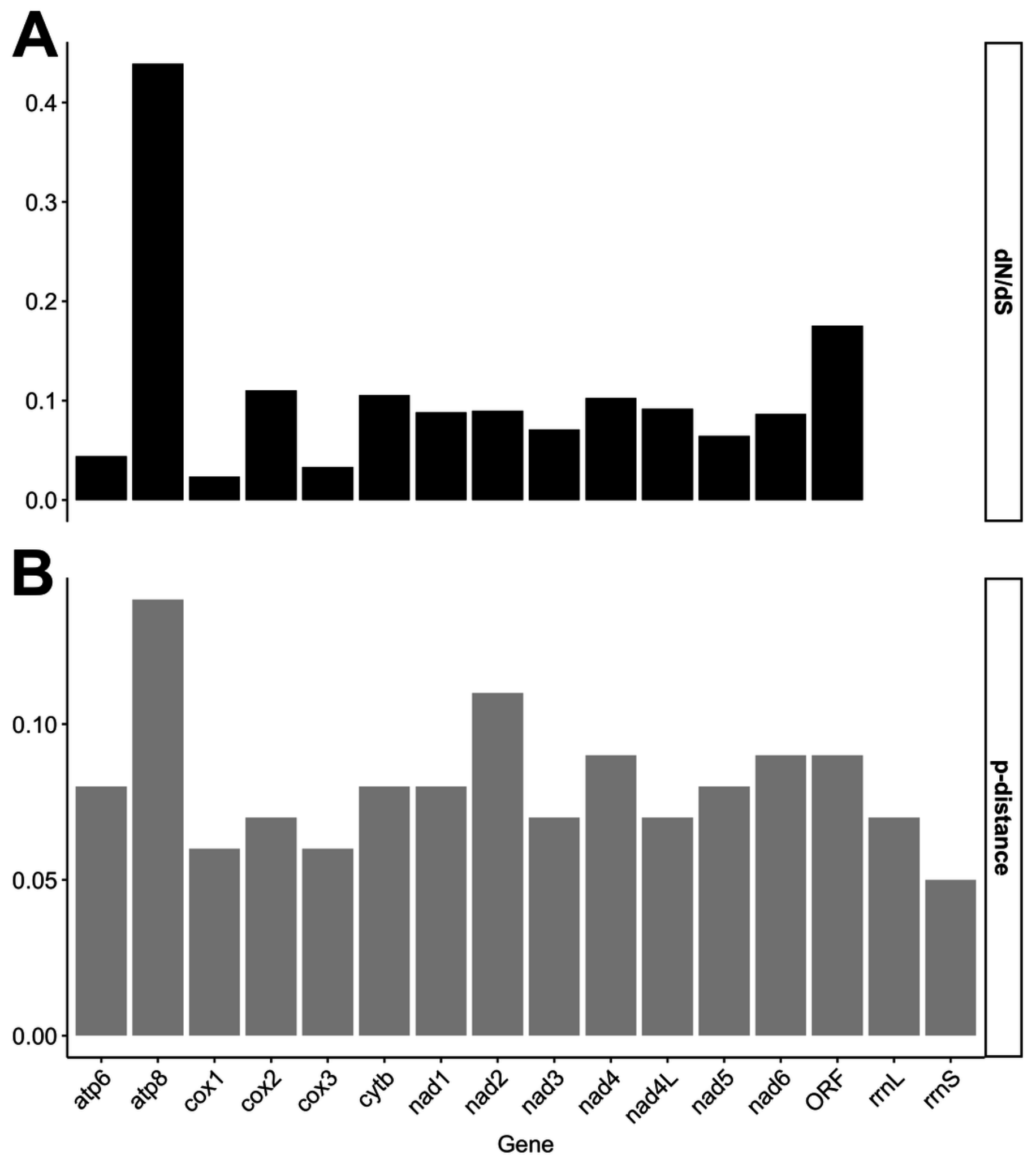


Figure 2

Bayesian inference (BI) trees produced in BEAUti and BEAST 2.4.6 for (A) f-orf, (B) cox1, and $(C)$ concatenated $f$-orf and cox 1 sequences also used in maximum likelihood trees of Fig. S2.

(A) was produced using a Hasegawa-Kishino-Yano model, (B) a Tamura-Nei model and (C) both these models of nucleotide substitution. Sequences used in BI trees refer to those listed and starred in Table 2. 
forf

Bayesian Inference Tree

$\mathrm{HKY}+\mathrm{G}+1$ Model

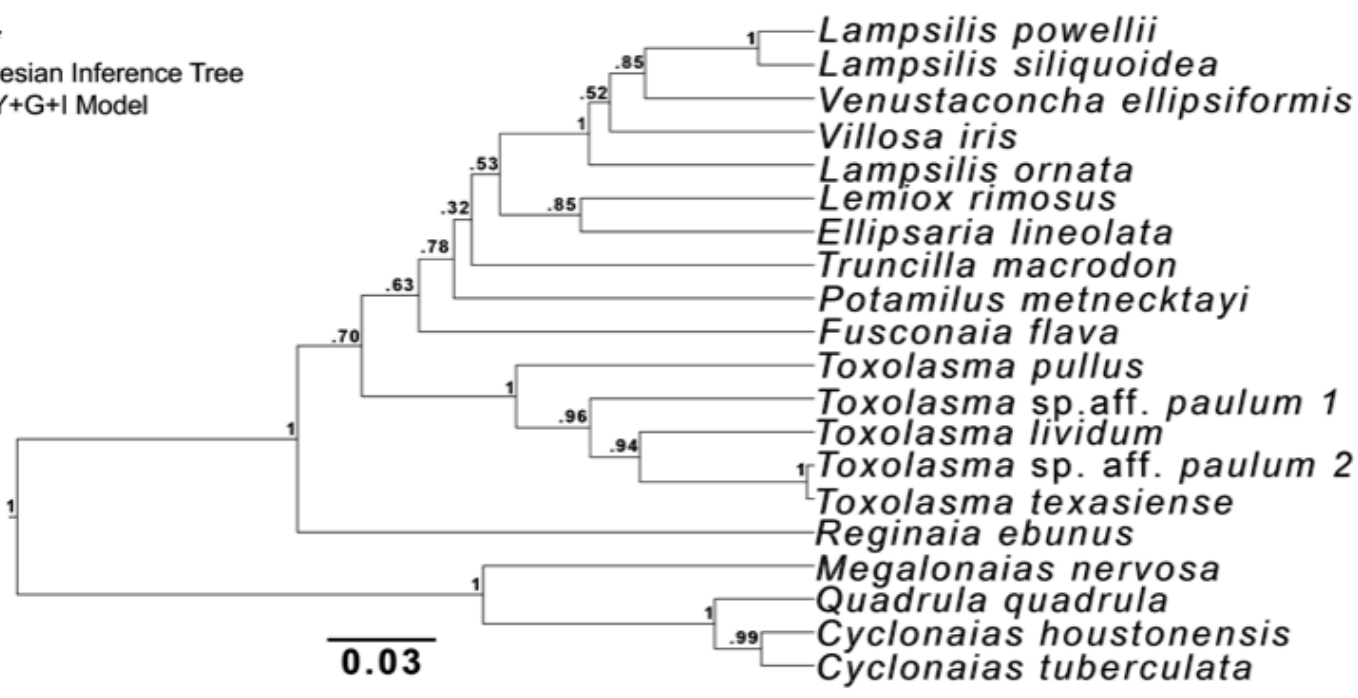

Lampsilini

Lampsilini

Pleurobemini

Lampsilini

Pleurobemini

Quadrulini

B

cox1

Bayesian Inference Tree TN93+G+I Model
Venustaconcha ellipsiformis Lampsilis siliquoidea

Lampsilis powellii

-Truncilla macrodon

Villosa iris

Ellipsaria lineolata

Lampsilis ornata

Lemiox rimosus

Potamilus metnecktayi

-Toxolasma sp.aff. paulum 1

-Toxolasma sp. aff. paulum 2

Toxolasma lividum

Toxolasma texasiense

Fusconaia flava

Reginaia ebunus

Megalonaias nervosa

Quadrula quadrula

Cyclonaias tuberculata

Cyclonaias houstonensis

C

f-orf + cox 1

Bayesian Inference Tree

$\mathrm{HKY}+\mathrm{G}+\mathrm{I}$ Model (f-orf)

TN93+G+I Model (cox1)

Ellipsaria lineolata

Lemiox rimosus

Lampsilis ornata.

Lampsilis powellii

- Lampsilis siliquoidea

Venustaconcha ellipsiformis Villosa iris

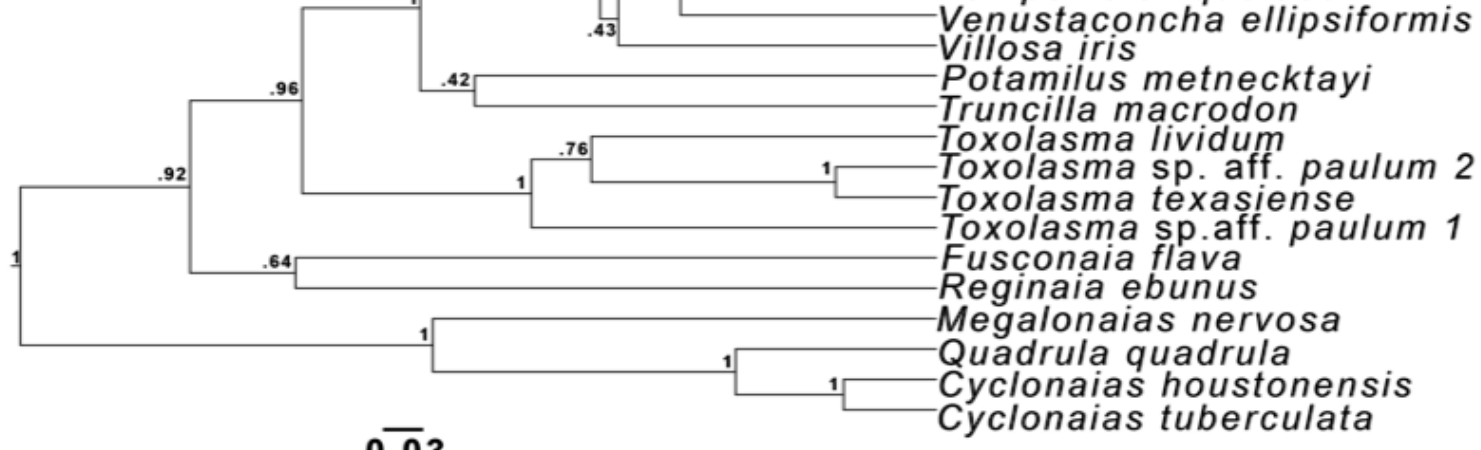

Lampsilini

Pleurobemini

0.03

Cyclonaias tuberculata 
Figure 3

The distribution of pair-wise $p$-distance scores for $f$-orf and cox 1 genes within Ambleminae.

The taxa compared are listed in Table 2. Intrageneric comparisons exclude intraspecific comparisons.

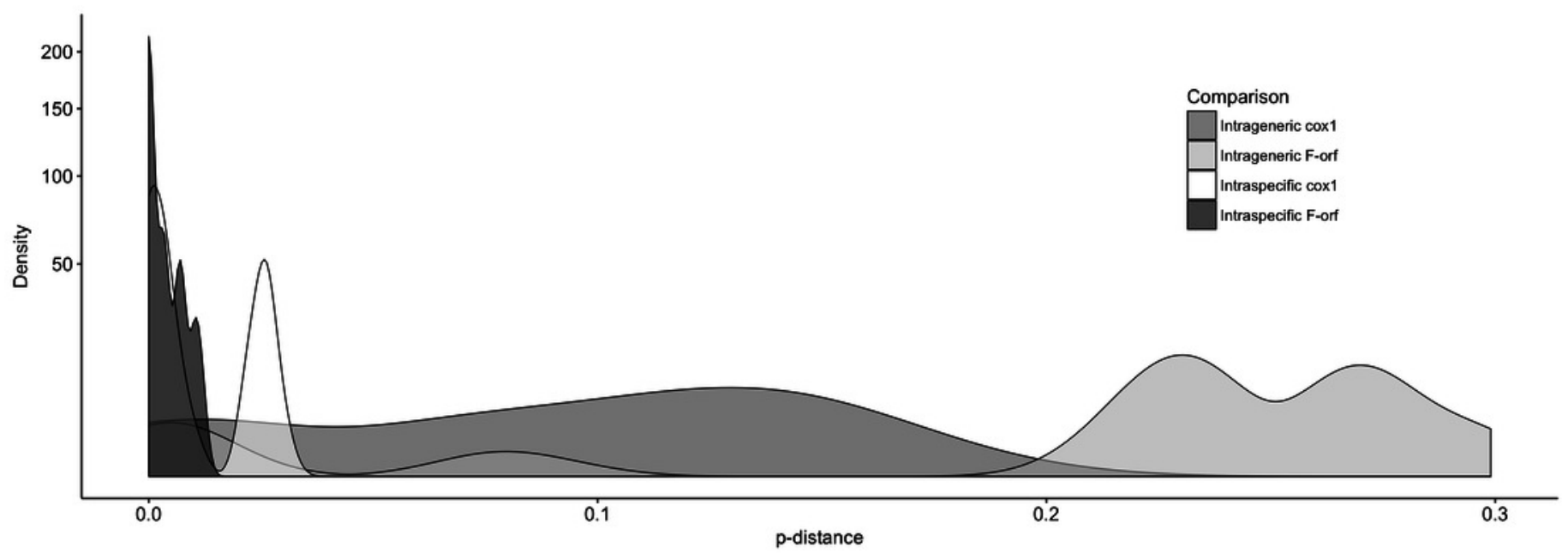




\section{Table 1 (on next page)}

Primers pairs used in the amplification of the entire $\mathrm{F}$ genomes. 
Table 1. Primers pairs used in the amplification of the entire $F$ genomes.

\begin{tabular}{lll}
\hline $\begin{array}{l}\text { Mitotype } \\
\text { Region } \\
\text { (Amplicon Size) }\end{array}$ & Primer name & Primer sequence (5' to 3') \\
\hline F genome & & \\
cox2 $-r r n L$ & $*$ UNIOCOII.2 ${ }^{\mathrm{a}}$ & CAGTGGTATTGGAGGTATGAGTA \\
$(\sim 11 \mathrm{~kb})$ & Ambl16SFor $^{\mathrm{c}}$ & CTGGGTTTGCGACCTCGATGTTGGCTTAGGGAAA \\
$\operatorname{cox} 1-r r n L$ & $*$ HCO-700y2 $2^{\mathrm{b}}$ & TCAGGGTGACCAAAAAAYCA \\
$(\sim 5.5 \mathrm{~kb})$ & Ambl16SRev $^{\mathrm{c}}$ & TTTCCCTAAGCCAACATCGAGGTCGCAAACCCAG \\
\hline
\end{tabular}

NOTE - For primer names: Ambl and $*=$ Amblemine-specific primers.

a From Curole \& Kocher, 2002.

b From Walker et al., 2006.

c See Breton et al., 2011. 


\section{Table 2 (on next page)}

Cox 1 and $f$-orf sequences used in Ambleminae phylogenies and in analysis of $f$-orf and cox1 sequences variability. 
Table 2. Cox 1 and $f$-orf sequences used in Ambleminae phylogenies and in analysis of $f$ orf and coxl sequences variability.

\begin{tabular}{|c|c|c|c|c|}
\hline \multirow[t]{2}{*}{ Species } & \multicolumn{2}{|l|}{$\operatorname{cox} 1$} & \multicolumn{2}{|l|}{ f-orf } \\
\hline & Accession & Reference & Accession & Reference \\
\hline \multirow[t]{3}{*}{ Ellipsaria lineolata } & AY654994 & Campbell et al., 2005 & HM849378* & Breton et al., 2011 \\
\hline & GU085285* & Boyer et al., 2011 & - & - \\
\hline & HM849071 & Breton et al., 2011 & - & - \\
\hline \multirow[t]{4}{*}{ Fusconaia flava } & DQ298537* & Burdick \& White, 2007 & HM849380 & Breton et al., 2011 \\
\hline & DQ298538 & Burdick \& White, 2007 & HM849381* & Breton et al., 2011 \\
\hline & EF033261 & Chapman et al., 2008 & HМ849382 & Breton et al., 2011 \\
\hline & HM849073 & Breton et al., 2011 & - & - \\
\hline \multirow[t]{2}{*}{ Lampsilis ornata } & AF385112 & Roe et al., 2001 & AY365193* & Serb \& Lydeard, 2003 \\
\hline & AY365193* & Serb \& Lydeard, 2003 & - & - \\
\hline \multirow[t]{2}{*}{ Lampsilis powellii } & HM849075* & Breton et al., 2011 & MF326971* & This study \\
\hline & - & - & HM849384 & Breton et al., 2011 \\
\hline \multirow[t]{2}{*}{ Lampsilis siliquoidea } & HМ849076 & Breton et al., 2011 & MF326973* & This study \\
\hline & - & - & HM849385 & Breton et al., 2011 \\
\hline \multirow[t]{3}{*}{ Lemiox rimosus } & AY655002* & Campbell et al., 2005 & - & - \\
\hline & EF033256 & Chapman et al., 2008 & - & - \\
\hline & HМ849093 & Breton et al., 2011 & - & - \\
\hline Megalonaias nervosa & AY655007* & Breton et al., 2011 & HМ849404* & Breton et al., 2011 \\
\hline \multirow[t]{2}{*}{ Potamilus metnecktayi } & HМ849099* & Breton et al., 2011 & HМ849405* & Breton et al., 2011 \\
\hline & - & - & HМ849406 & Breton et al., 2011 \\
\hline \multirow[t]{2}{*}{ Quadrula quadrula } & FJ809750* & Breton et al., 2009 & FJ809750* & Breton et al., 2009 \\
\hline & KX853888-982 & Mathias et al., 2018 & - & - \\
\hline \multirow[t]{3}{*}{ Reginaia ebenus } & AY654999 & Unpublished & HM849379* & Breton et al., 2011 \\
\hline & HM849072 & Breton et al., 2011 & - & - \\
\hline & KF035133* & Inoue et al., 2013 & - & - \\
\hline \multirow{2}{*}{$\begin{array}{l}\text { Cyclonaias } \\
\text { houstonensis }\end{array}$} & KT285649* & Pfeiffer et al., 2016 & HM849440* & Breton et al., 2011 \\
\hline & - & - & HМ849441 & Breton et al., 2011 \\
\hline \multirow[t]{2}{*}{ Cyclonaias tuberculata } & GU085284* & Boyer et al., 2011 & HM849376* & Breton et al., 2011 \\
\hline & HM849069-70 & Breton et al., 2011 & HM849377 & Breton et al., 2011 \\
\hline \multirow[t]{2}{*}{ Toxolasma lividum } & AF231756* & Bogan \& Hoeh, 2000 & HМ849451-55 & Breton et al., 2011 \\
\hline & JF326436 & $\begin{array}{l}\text { Campbell \& Lydeard, } \\
2012\end{array}$ & HM849456* & Breton et al., 2011 \\
\hline \multirow[t]{3}{*}{ Toxolasma paulum spl } & HM849131* & Breton et al., 2011 & HM849458 & Breton et al., 2011 \\
\hline & HM849133 & Breton et al., 2011 & HM849459-63 & Breton et al., 2011 \\
\hline & - & - & HM849464* & Breton et al., 2011 \\
\hline \multirow[t]{3}{*}{ Toxolasma paulum sp 2} & HМ849129* & Breton et al., 2011 & HМ849465-73 & Breton et al., 2011 \\
\hline & HM849130 & Breton et al., 2011 & HM849474* & Breton et al., 2011 \\
\hline & HM849132 & Breton et al., 2011 & HМ849475 & Breton et al., 2011 \\
\hline Toxolasma pullus & - & - & MF326970* & This study \\
\hline \multirow[t]{2}{*}{ Toxolasma texasiense } & AY655023* & Campbell et al. 2005 & HМ849476 & Breton et al., 2011 \\
\hline & - & - & HМ849477* & Breton et al., 2011 \\
\hline \multirow[t]{2}{*}{ Truncilla macrodon } & HM849165* & Breton et al., 2011 & HМ849478* & Breton et al., 2011 \\
\hline & KT285658 & Pfeiffer et al., 2016 & & \\
\hline \multirow{3}{*}{$\begin{array}{l}\text { Venustaconcha } \\
\text { ellipsiformis }\end{array}$} & EF033260* & Chapman et al., 2008 & FJ809753 & Breton et al., 2009 \\
\hline & - & - & HM849529* & Breton et al., 2011 \\
\hline & - & - & HM849530 & Breton et al., 2011 \\
\hline \multirow[t]{3}{*}{ Villosa iris } & HM849199* & Breton et al., 2011 & HМ849531 & Breton et al., 2011 \\
\hline & HM849200-1 & Breton et al., 2011 & HМ849532* & Breton et al., 2011 \\
\hline & - & - & HM849533 & Breton et al., 2011 \\
\hline
\end{tabular}

2 NOTE - Cox 1 sizes range from 339 to $1541 \mathrm{bp}$. F-orf sizes range from 240 to $410 \mathrm{bp}$. Note that for trees sequences 3 were trimmed to a common start and end position in alignments.

$4 *$ Sequences that were specifically used in Ambleminae phylogenies. 